\title{
Functional Outcome of Osteosynthesis in Intracapsular Fracture of Femoral Neck with Delayed Presentation - A Retrospective Study
}

\author{
Dr. Manoj Kumar H. V', Dr. Hemanth H. P. ${ }^{2}$, Dr. Karan Shetty ${ }^{3}$, Dr. Krishnamurthy $T^{4}$ \\ ${ }^{1}$ Professor, Department of Orthopaedics, Bangalore Medical College and Research Institute, Bangalore, Karnataka, India \\ ${ }^{2}$ Senior Resident, Department of Orthopaedics, Bangalore Medical College and Research Institute, Bangalore, Karnataka, India \\ ${ }^{3}$ Post-graduate, Department of Orthopaedics, Bangalore Medical College and Research Institute, Bangalore, Karnataka, India \\ ${ }^{4}$ Senior Resident, Department of Orthopaedics, Bangalore Medical College and Research Institute, Bangalore, Karnataka, India
}

\begin{abstract}
Surgical management of fracture Neck of Femur is dictated by physiological age of the patient. An Intracapsular fracture of neck of Femur in adults is relatively uncommon and is difficult to manage. The study intends to analyze the functional outcome of Femoral neck fracture in adults below 60yrs of age treated surgically by internal fixation following delayed presentation more than 48 hrs after trauma.
\end{abstract}

Keywords: Osteosynthesis, Intracapsular, Fracture, Femoral Neck, Delay Presentation

\section{Introduction}

Surgical management of fracture neck of femur is partly dictated by the physiological age of the patient. Patients that present with femoral neck fractures fall into one of two evidence-based age categories: "young" and "old." These categories are based on the patient's physiological age, not chronological age. "Young" patients are those with good bone stock that can maintain internal fixation, and the goal of treatment is joint preservation. ${ }^{1}$

An Intracapsular fracture of the neck of the femur in the young adult are relatively uncommon, and is a difficult injury to manage. ${ }^{1,2}$ While undisplaced fractures (Garden types 1 and 2) almost always unite, nonunion and avascular necrosis (AVN) of the femoral head are the two major complications of displaced type- 3 and type- 4 fractures. 3,4

Early reduction and fixation of femoral neck fractures is directed at the idea that the tenuous blood supply to the femoral head may be stretched or kinked by the injury, and that early fracture reduction allows restoration of the blood flow. Delayed fixation ( $>48$ hours) is reported to have to have poorer outcomes in terms of greater incidence of non-union and avascular necrosis of femoral head. ${ }^{1}$

Currently, there are conflicting views in the literature regarding the optimal time to internal fixation. It has been postulated that early internal fixation drastically reduces the incidence of osteonecrosis of the femoral head. However, there is a paucity of literature looking at the effect of time delay to internal fixation on the development of this late complication.

This study intends to analyze the functional outcomes of femoral neck fractures in adults below 60 years of age treated surgically by internal fixation following delayed presentation - more than 48 hours after trauma.

\section{Materials and Methods}

Fifty one patients under the age of 60 years presenting with intracapsular femoral neck fracture between 2009 and 2014 were identified. Of these, three patients were treated with total hip replacement and three with bipolar hemiarthroplasty. These patients were excluded from the study. No follow-up data was available for five patients, so these patients were also excluded from the data. Therefore, 40 patients under the age of 60 were included.The operations were performed between 2009 and 2014, at Bowring and Lady Curzon Hospital, attached to Bangalore Medical College and Research Institute.

Patients below 60 years of age with femur neck fractures who presented $>48$ hours following trauma, who were treated by internal fixation, were included in the study. All patients were treated at a tertiary level teaching hospital.

Exclusion criteria included associated fractures in the ipsilateral limb, osteosynthesis of femoral neck fracture done with bone grafting or osteotomy, pathologic fractures, osteomyelitis and fracture in a paralytic limb. In addition, we excluded patients whose case records could not retrieved and patients lost on follow up.

With approval from the Ethical Review Committee, patients were identified through the medical records department. Information was collected regarding patient age, gender, medications (including use of prednisone), comorbidities, type of femoral neck fracture (displaced or undisplaced), use of preoperative traction, time to operative treatment, operative details, postoperative weight-bearing status, and complications.

All patients were examined to determine the development of avascular necrosis, and the rates of avascular necrosis were analyzed with respect to potential predictor variables - age, fracture displacement, time to fracture reduction, and type of fixation (a sliding hip screw or three 


\section{International Journal of Science and Research (IJSR) \\ ISSN (Online): 2319-7064 \\ Index Copernicus Value (2013): 6.14 | Impact Factor (2015): 6.391}

cannulated screws). All patients whom we were able to contact were asked to return for radiographic follow-up, and the development of avascular necrosis was determined on the most recent radiographs available. Preoperative and postoperative radiographs of the hip and pelvis (anteroposterior and frog-leg lateral views) were also evaluated for the quality of fracture reduction, adequacy of fixation, fracture-healing, and preexisting avascular necrosis. Acceptability of fracture reduction was evaluated based on Garden's alignment index.

Function was measured with use of the Harris Hip Score, the Western Ontario and McMaster University (WOMAC) Osteoarthritis Index, and visual analogue scale after a minimum of two years of follow-up.

\section{Results}

\section{Demographic and Clinical Characteristics}

Falls accounted for twenty four of the hip fractures, and motor-vehicle accidents accounted for the other sixteen cases. All cases were fixed following closed reduction. Thirty two patients had a displaced fracture, with a mean time to surgery of $32.3 \pm 14.5$ hours. Eight patients had an undisplaced fracture, with a mean time to surgery of 40.9 \pm 29.2 hours.
Thirty three patients were treated with multiple cannulated screws, while seven were treated with a sliding hip screw. All patients were kept non-weight-bearing immediately after the surgery, and partial weight bearing allowed at 6 weeks follow-up, in the presence of satisfactory union in progress. Four cases developed non-union, of which three later underwent total hip arthroplasty and one underwent hemiarthroplasty. The mean time to union in the remaining cases was $18 \pm 2.4$ weeks.

In the series as a whole, avascular necrosis was seen in three cases; two of which were following fixation by sliding hip screw, and one following fixation with CC screws. The average duration of follow-up before assessment of functional outcome was $3.4 \pm 1.3$ years).

\section{Radiographic Evidence of Avascular Necrosis}

Radiographic evidence of avascular necrosis developed in three $(7.5 \%)$ of the entire group of forty patients. All three cases had displaced femoral neck fractures. All radiographs showed that the placement of the sliding hip screw or multiple screws was adequate, i.e., either central or inferior within the femoral head. The reduction was nearly anatomic in all cases but one patient whose reduction was in slight varus, with unsatisfactory spanning of CC screws went on to develop avascular necrosis.

\begin{tabular}{|l|c|}
\hline \multicolumn{2}{|c|}{ Characteristics of patients treated with fracture fixation > 48 hours after injury } \\
\hline Number of Patients & 40 \\
\hline Female & 12 \\
\hline Male & 28 \\
\hline Mean Age (Standard deviation) at time of injury (years) & $50.5 \pm 6.9$ \\
\hline Displaced fracture & 32 \\
\hline Undisplaced fracture & 8 \\
\hline Preoperative traction & 16 \\
\hline Average time to surgery (hours) & $40.9 \pm 29.2$ \\
\hline - Undisplaced fractures & $32.3 \pm 14.5$ \\
\hline- Displaced fractures & 7 \\
\hline Fracture fixation & 33 \\
\hline$-\quad$ Sliding hip screw & 3 \\
\hline- & \\
\hline Cannulated screws & 1 \\
\hline- & 2 \\
\hline Cannulated screws & \\
\hline Sliding hip screw & \\
\hline 1 & 0 \\
\hline $2 \quad$ onsification of avascular necrosis & 1 \\
\hline 3 & 1 \\
\hline 4 & 1 \\
\hline
\end{tabular}

Volume 5 Issue 6, June 2016 www.ijsr.net 
International Journal of Science and Research (IJSR)

ISSN (Online): 2319-7064

Index Copernicus Value (2013): 6.14 | Impact Factor (2015): 6.391

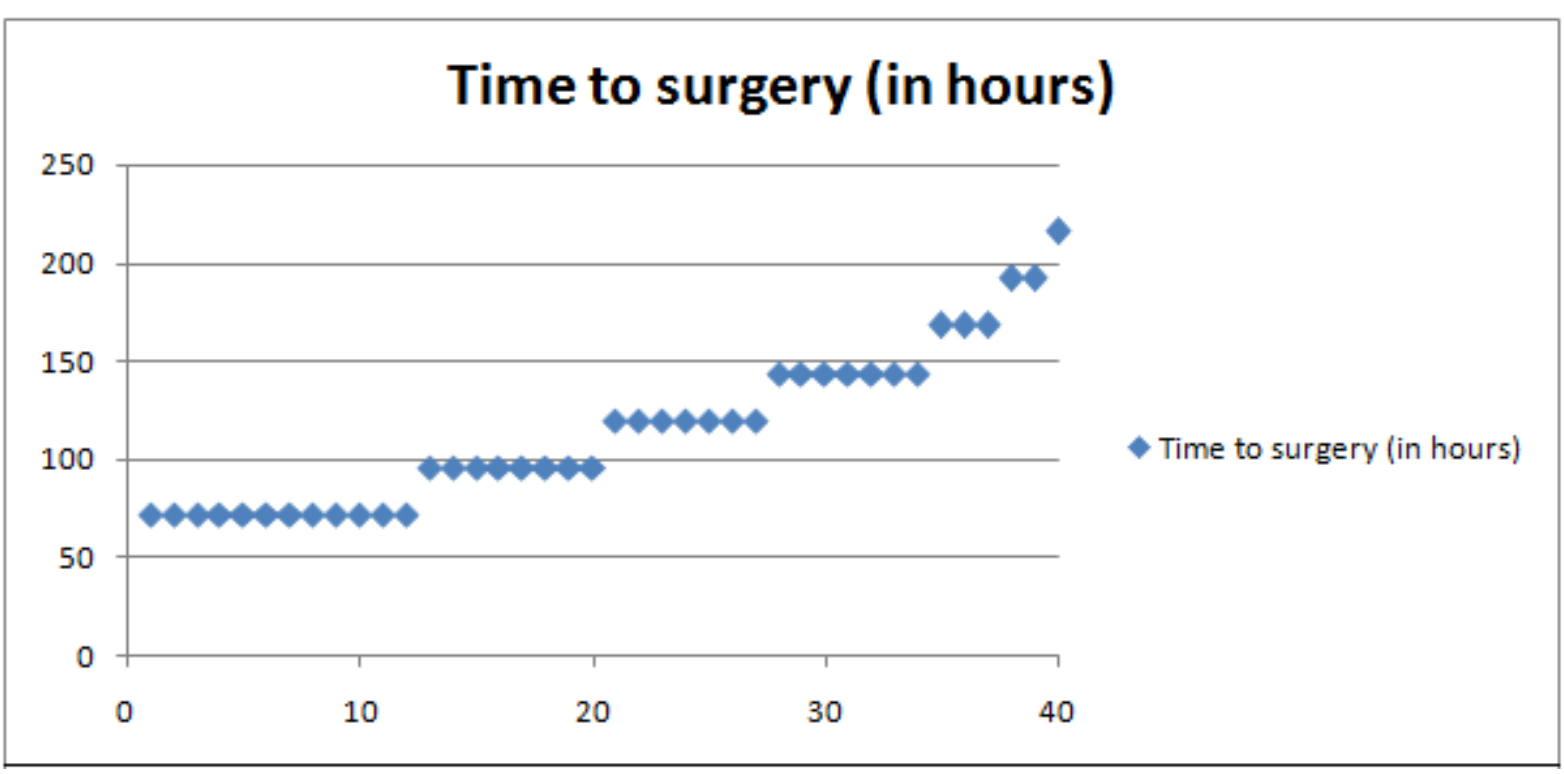

\section{Functional Outcomes}

With regard to the Harris Hip Score categories of pain, limp, support, distance walked, climbing stairs, sitting, deformities, range of motion and function, 29 cases had excellent outcomes, 6 had good outcomes, 4 fair, and one patient had a poor functional HHS. The mean (and standard deviation) was $91.0 \pm 6$ points.

The functional outcomes were also found to be comparable between the three patients in whom radiographic evidence of avascular necrosis developed and the patients who did not have signs of avascular necrosis.

Table 1: Functional Outcome

\begin{tabular}{|c|c|}
\hline \multicolumn{2}{|c|}{ Functional Outcome (Harris Hip Score) } \\
\hline Excellent $(>90)$ & 29 \\
\hline Good $(80-89)$ & 6 \\
\hline Fair $(70-79)$ & 2 \\
\hline Poor $(<69)$ & 1 \\
\hline
\end{tabular}
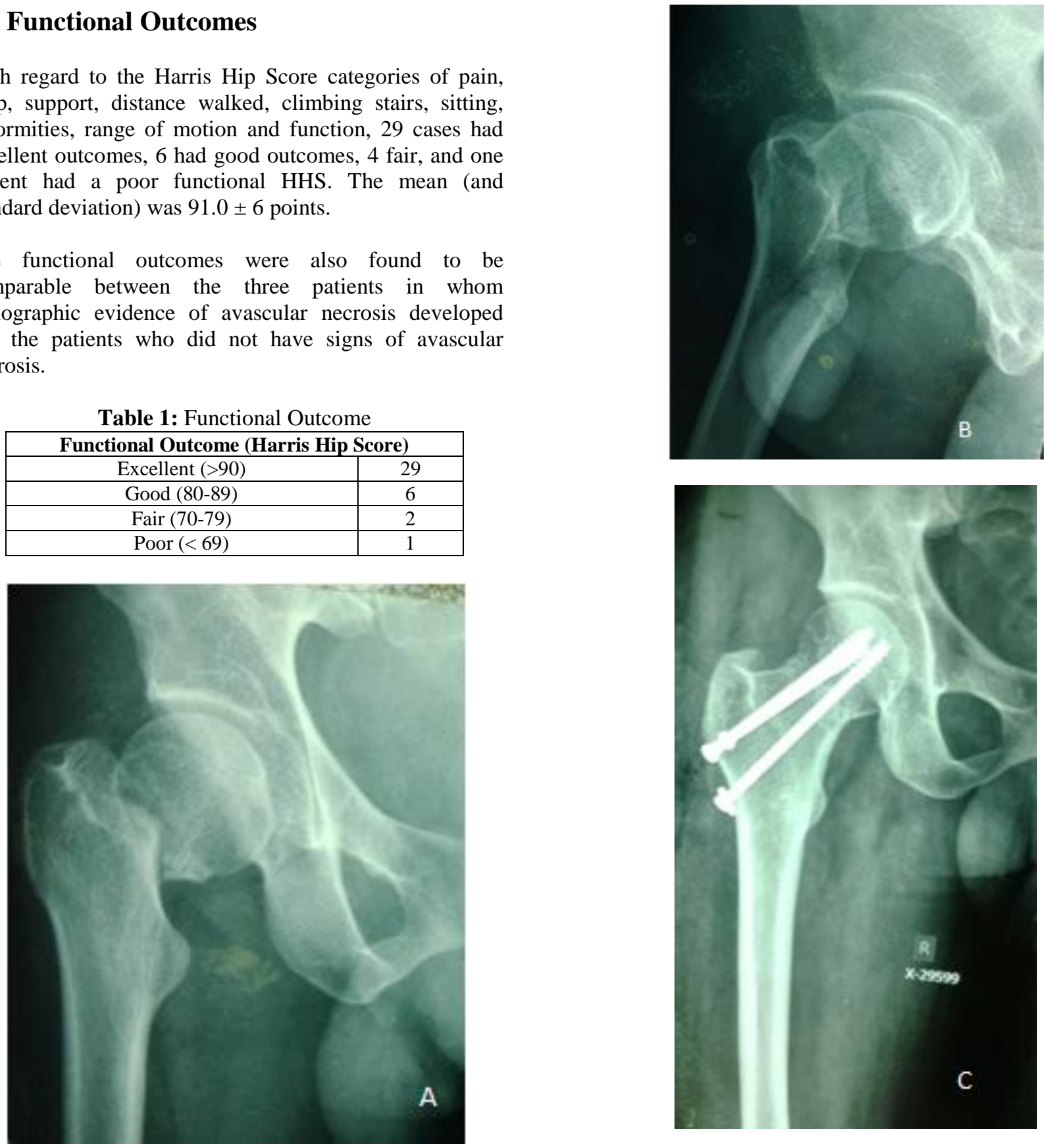

Volume 5 Issue 6, June 2016 www.ijsr.net

Licensed Under Creative Commons Attribution CC BY 

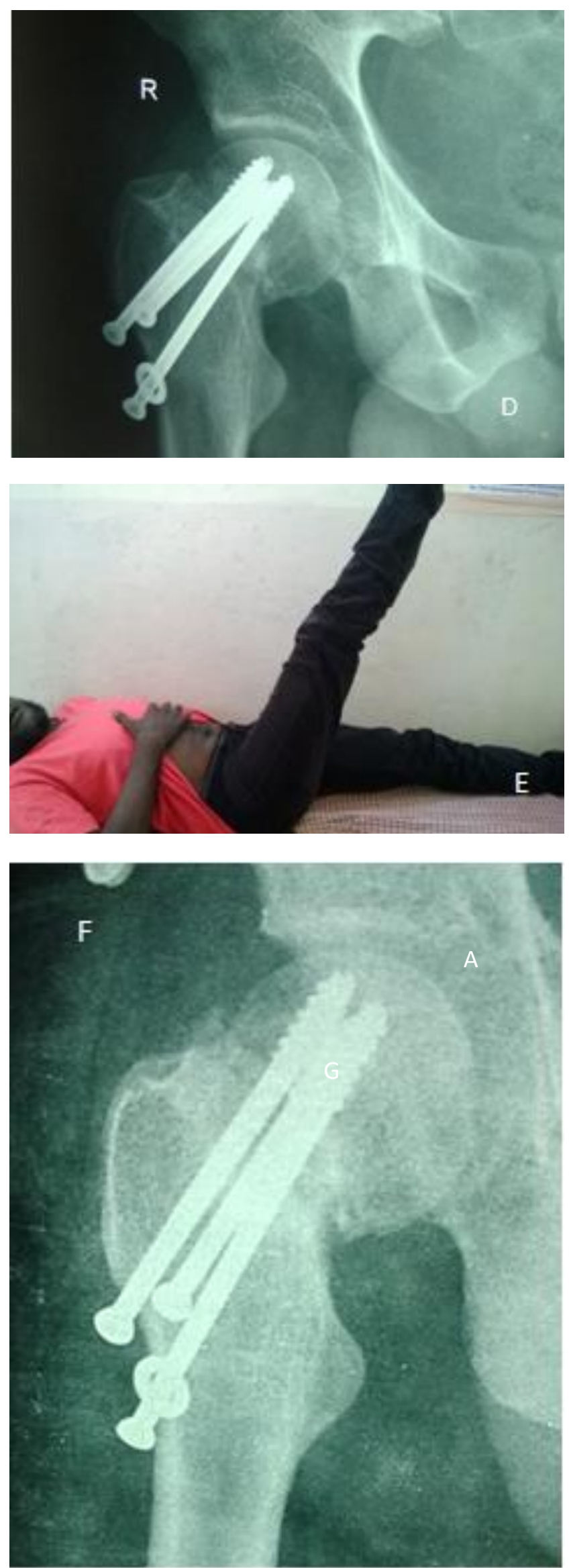

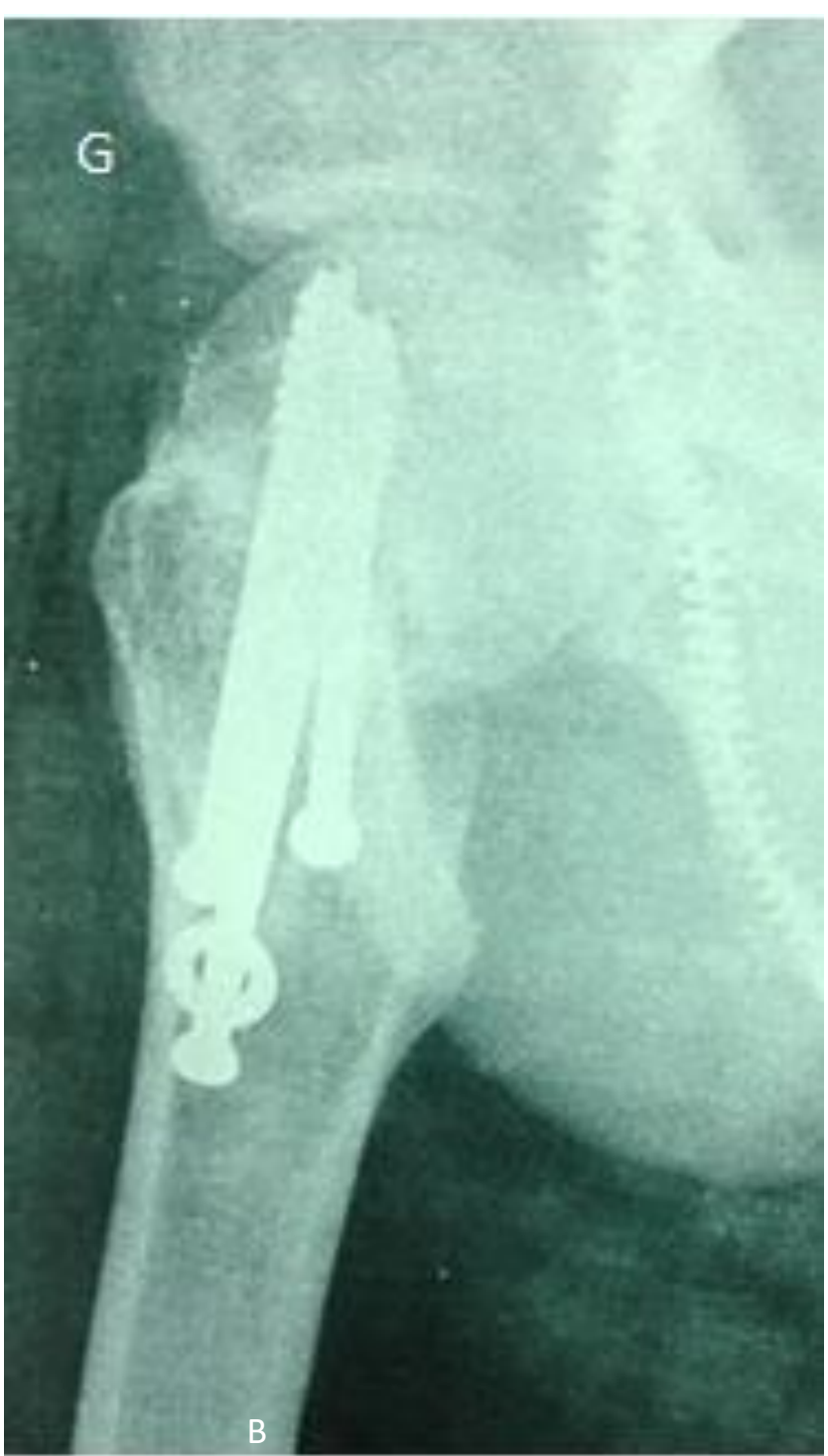

A 41 year male sustained displaced intracapsular femoral neck fracture (A, B) which was fixed internally by cancellous screws (C). At 12 weeks follow up (D) mild varus collapse with union in progress. At 24 weeks follow up there is good union $(\mathrm{F}, \mathrm{G})$ with excellent hip function (E) on HHS scoring.

\section{Complications}

Four cases developed non-union in that three cases underwent total hip arthroplasty, while one underwent hemiarthroplasty. Radiographic evidence of Avascular necrosis was seen in three cases, however all three patients were asymptomatic and had good functional hip scores. These patients were however counseled about the possible need for resurgery, either in the form of muscle pedicle bone grafting or total hip arthroplasty in the future.

No deaths, deep venous thromboses or wound infections were noted in the study group. 


\section{International Journal of Science and Research (IJSR) \\ ISSN (Online): 2319-7064}

Index Copernicus Value (2013): 6.14 | Impact Factor (2015): 6.391

\section{Discussion}

The rates of nonunion and AVN which have been reported after internal fixation vary widely. In various studies, nonunion has ranged from $4 \%$ to $59 \%$ and AVN from $10 \%$ to $86 \%$. $^{5,6,7}$

Fracture of the neck of the femur is traditionally treated by an emergency operation. Swiontkowski et $\mathrm{al}^{8}$, in a series of 27 patients belonging to a similar age group, achieved union of $100 \%$ when surgery was performed within eight hours of the injury. This high rate of union may have been influenced by the number $(30 \%)$ of undisplaced Garden grade II fractures among their patients. However, $20 \%$ of the patients developed AVN. Zetterberg et $\mathrm{al}^{9}$ and Bray ${ }^{10}$ also suggested that the timing of surgery after injury was an important factor in influencing the outcome.

Most contemporary studies do not identify an association between time to surgery and development of AVN or nonunion. Haideukewych et $\mathrm{al}^{11}$ retrospectively compared 73 patients between ages $15-50$ treated for femoral neck fractures. Those patients treated within 24 hours of injury demonstrated AVN $23 \%$ of the time, and $7 \%$ developed nonunions. Those treated after 24 hours developed AVN $20 \%$ of the time and $10 \%$ developed nonunion.

Upadhyay $^{12}$ evaluated 92 patients less than 50 years old with femoral neck fractures and overall rate of AVN of 16 $\%$ with no difference in treatment before or after 48 hours.

We found that internal fixation was equally effective within one week of injury. We found no difference in the functional results between the six patients in whom radiographic evidence of avascular necrosis developed and those in whom it did not.

A shortcoming of our study was the small number of subjects. Femoral neck fractures are not common in young adults, so acquisition of such a statistically significant sample size would require a large multicenter trial. A prospective, randomized clinical trial involving multiple sites is certainly possible.

In conclusion, avascular necrosis was associated with a delay of more than 48 hours before the fixation of intracapsular femoral neck fractures. Nonetheless, functional outcomes were similar between the early and delayed fixation groups at an average of two years follow up. Longer and more complete functional and radiographic follow-up is required to evaluate the functional consequences of avascular necrosis over time. Our study suggests that there may be an advantage to early fixation of intracapsular femoral neck fractures in terms of reducing radiographic evidence of avascular necrosis, although function may not necessarily be affected in the first few years following injury.

\section{References}

[1] Ly TV, Swiontkowski MF. Treatment of femoral neck fractures in young adults. Instr Course Lect. 2009;58:69-81
[2] Askin, S. R. and Bryan, R. S.: Fernoral Neck Fractures in Young Adults. Clin. Orthop. ,114: 259264. 1976.

[3] Swiontkowski MF. Intracapsular fractures of the hip. J Bone Joint Surg Am. 1994;76(1):129-38.

[4] Vertelis A, Petrulis A, Jermolajevas V. Treatment results of displaced femoral neck fractures. Methods. 2002;38(5):505-9.

[5] Gautum VK, Anand S, Dhaon BK. Management of displaced femoral neck fractures in young adults (a group at risk). Injury 1998;29:215-18.

[6] Gerber C, Strehle J, Ganz R. The treatment of fractures of the femoral neck. ClinOrthop 1993;292:77-86.

[7] Protzman RR, Burkhalter WE. Femoral neck fractures in young adults. J Bone Joint Surg [Am] 1976;58A:689-95.

[8] Swiontkowski MF, Winquist RA, Hansen Jr ST. Fractures of the femoral neck in patients between the ages of twelve and forty-nine years. J Bone Joint Surg Am. 1984;66:837-46

[9] Zetterberg CH, Irstam L, Andersson GBJ. Femoral neck fractures in young adults. Acta Orthop Scand 1982;53:427-35

[10] Bray TJ. Femoral neck fracture fixation. Clin Orthop 1997;339:20-31

[11] Haidukewych GJ, Rothwell WS, Jacofsky DJ, Torchia ME, Berry DJ. Operative treatment of femoral neck fractures in patients between the ages of fifteen and fifty years. J Bone Joint Surg Am. 2004;86:1711-6. This retrospective study is one of the more recent ones looking at the correlation of timing to surgery and outcomes of AVN and nonunion in young patients

[12] Upadhyay A, Jain P, Mishra P, et al. Delayed internal fixation of fractures of the neck of the femur in young adults. A prospective, randomised study comparing closed and open reduction. J Bone Joint Surg Br 2004;86(7):1035-40 